\title{
Chemical defence in a sawfly: genetic components of variation in relevant life-history traits
}

\author{
C Müller ${ }^{1}$, BJ Zwaan, H de Vos and PM Brakefield \\ Institute of Biology, Leiden University, PO Box 9516, NL-2300 RA Leiden, The Netherlands
}

\begin{abstract}
Larvae of several tenthredinid sawfly species readily release droplets of haemolymph through their integument when attacked by predators. This defence mechanism via 'bleeding' is characterised by a low integument resistance and a high haemolymph deterrence. Both traits are variable, and negatively correlated among species. We sought to determine if such differences in the propensity to bleed also occur intraspecifically by studying the heritability of traits potentially associated with the bleeding phenomenon in the turnip sawfly Athalia rosae ruficornis Jakovlev (Hymenoptera: Tenthredinidae, Allantinae). For three European populations, heritabilities were estimated in the laboratory in a parentoffspring and a full-sib design for haemolymph deterrence (measured as concentration of sequestered glucosinolate), integument resistance, body mass of eonymph and adult, and developmental time. Within $A$. rosae, no significant
\end{abstract}

negative phenotypic correlation was found between the two traits directly related to the defence mechanism: integument resistance and haemolymph deterrence. However, the significant heritabilities found for these traits in the full-sib analysis $(0.39$ and 0.35 , respectively, for males in the Swiss population) show that the variation has a genetic component. While full-sib analysis revealed highly significant heritabilities for most traits in all the three populations, parent-offspring regression revealed little or no evidence of heritable variation. Effects of common environment for siblings and variation in the host-plant quality between insect generations are likely to be the main factors explaining these differences. A consequence of such host-plant variation in the wild might be that genetic variation of such chemical defensive traits is largely invisible to natural selection.

Heredity (2003) 90, 468-475. doi:10.1038/sj.hdy.6800265

Keywords: chemical defence; heritability; life history; quantitative genetics; sawfly

\section{Introduction}

Although traits related to chemical defence mechanisms of insect herbivores are directly subjected to natural selection, their genetic architecture is poorly understood. A few studies have measured genetic and phenotypic variation of chemical defences, for example, in species of beetles (eg Eggenberger and Rowell-Rahier, 1992; Holloway et al, 1993) or butterflies (Camara, 1997). Two arguments might explain the lack of more investigations of this type. Firstly, as the chemistry of the insect is often very closely linked to that of the host plant, chemical variation in the latter might overshadow genetic variation in the former. Secondly, the effort required to measure chemical variation qua time and technique is usually higher than for measurements of morphological or developmental traits, thus tending to lead to more limited sample sizes. Nevertheless, the intriguingly high diversity of chemical defence mechanisms utilised in sawflies through self-synthesised or sequestered toxins (Codella and Raffa, 1993) offers an interesting field for investigations. Several species of the tenthredinid sawflies exhibit a so-called 'easy bleeding' defence (Boevé and Schaffner, 2003); when the larvae are touched by, for

Correspondence: Caroline Müller, Institute of Biology, Leiden University, PO Box 9516, NL-2300 RA Leiden, The Netherlands.

E-mail: roca2911@hotmail.com

${ }^{1}$ Current address: University of Würzburg, Institute of Botany II, Juliusvon-Sachs-Platz 3, D-97082 Würzburg, Germany.

Received 6 August 2002; accepted 10 January 2003 example, pointed mandibles of a predator, their integument will disrupt readily at this spot and a droplet of haemolymph is released. This droplet has been shown to have deterrent effects on predators such as birds and ants (Ohara et al, 1993; Schaffner et al, 1994; Müller et al, 2002). The deterrent component is often derived from bioactive host-plant metabolites that are sequestered in the haemolymph of the sawflies (Schaffner et al, 1994; Müller et al, 2001; Boevé and Schaffner, 2003). Two quantitative traits characterise this bleeding phenomenon, namely the resistance of the integument and the haemolymph deterrence. These traits vary in different tenthredinid species and have been shown to be negatively correlated across 22 species (Boevé and Schaffner, 2003). A less-resistant integument results in a more rapid contact between the exuding haemolymph of the prey and an attacking predator, whereby this haemolymph apparently needs to be more toxic to deter a predator efficiently.

As tenthredinid species differ in their propensity to 'bleed', we sought to determine whether variation in traits associated with this defence mechanism occurs intraspecifically and whether it is heritable. Such quantitative genetic variation could then be the basis for macroevolutionary patterns (Schluter, 1996; Merilä and Björklund, 1999). The Turnip sawfly, Athalia rosae ruficornis Jakovlev (Hymenoptera: Tenthredinidae, Allantinae), was chosen for our study. A. rosae sequesters glucosinolates of its cruciferous host plants into the haemolymph (Müller et al, 2001). A deterrent effect on the ant species Myrmica rubra (Hymenoptera: 
Formicidae) is at least partly caused by this plant secondary metabolite (Müller et al, 2002). A. rosae is a haplodiploid insect and thus, unfertilised eggs develop into haploid males while fertilised eggs produce diploid females. An advantage of haplodiploids for studies of heritability is that there is no effect of dominance in the production of male offspring, and thus only additive genetic variance is estimated in sib analysis of brothers (Liu and Smith, 2000). Parent-offspring and sib analyses were carried out in the laboratory for potential traits related to the defence mechanism, and the phenotypic and genetic correlations between all the traits were examined. Sawflies from three different populations were studied to attempt to obtain a wider range of variation.

\section{Material and methods}

\section{Plants}

Plants of Sinapis alba L. (cultivar: Salvo, seeds from Advanta Seeds B.V., The Netherlands) were grown in a greenhouse $\left(20^{\circ} \mathrm{C}, 70 \%\right.$ relative humidity, L16:D8). Preflowering plants at 4-5 weeks were used.

\section{Insects}

A. rosae were collected as fertilised adult females while nectaring on Dipsacaceae at Autreppes, France (F). Larvae were collected from mustard fields both at Delémont, Switzerland $(\mathrm{CH})$ and Mühlheim, Germany (D). Adults were provided with honeywater-soaked cottonwool. Larvae were reared on shoots or leaves of S. alba. Eonymphs (the final, nonfeeding larval instar) were offered a mixture of sand and soil for pupation.

Offspring of individual females from France were reared as separate families. In the next generation, crosses of females were made to males of unrelated families of the same population to minimise inbreeding. The resulting adults and those that emerged from the larvae collected at Switzerland and Germany were used as the grandparent (GP) generation for the heritability studies in which all the three populations were analysed separately. Insects were reared at $22^{\circ} \mathrm{C}, 70 \%$ relative humidity, and L16:D8 in the Leiden laboratory. Plant material for all families of one generation was of the same age, and shoots or leaves were picked at random from plants.

\section{Heritability studies}

In the GP generation, one-half of the females was not mated to produce male offspring. The other half were mated individually to males, by placing couples together in Petri dishes for 1 day. Virgin and mated females were allowed to oviposit for $24 \mathrm{~h}$ on individual shoots of $S$. alba at 3-4 days after emergence from pupa when the number of mature eggs reaches a maximum in females (Sawa and Oishi, 1989). After 14days of common development on the shoot, larval offspring (parentgeneration $P$ ) were counted and five to 10 larvae of each family placed individually in Petri dishes lined with moist filter paper. Larvae were provided daily with freshly picked $S$. alba leaves.

Integument resistance was measured (see below) on the second day of the final feeding larval instar (males 4 th, females 5th instar). For larvae of the Swiss $P$ and male F1-generation, haemolymph samples of about $2 \mu 1$ were collected from the resulting wound, weighed in Eppendorf caps $(1.5 \mathrm{ml})$ and frozen at $-80^{\circ} \mathrm{C}$ for later analysis of glucosinolate concentration (see below).

When larvae reached their eonymph stage, they were weighed and placed in plastic cups (diameter: $5 \mathrm{~cm}$, height: $6.5 \mathrm{~cm}$ ) filled to $2 \mathrm{~cm}$ height with a mixture of sieved sand and soil in which they formed cocoons to pupate. After 1 week, cocoons were carefully removed and placed in Petri dishes lined with moistened filter paper. Adult mass was measured on the day of emergence. Developmental times both from egg to eonymph and from eonymph to adult were recorded.

$P$-adults were set up in a half-sib design. Males from a range of families were each mated to two to three individual females from different families. Matings were made assortatively based on high $(>3 \mathrm{~g})$ and low $(<3 \mathrm{~g})$ integument resistance values to increase the precision of the heritability estimates (Falconer and Mackay, 1996). Mated females, as well as individual virgin females, were allowed to oviposit on individual $S$. alba shoots for 1 day, 3-4 days after emergence. After 14 days, seven to 10 F1 larvae per family were taken randomly and placed individually into Petri dishes. Quantitative traits were measured sequentially as in the parent generation. As the number of female offspring in the $F 1$ was very low, an additional generation of mated females from the French and Swiss populations was set up for oviposition, and the same traits measured in the $F 2$.

\section{Measurement of integument resistance}

An advanced force gauge (Mecmism, AFG 2.5 N) with an iron needle (diameter: $0.2 \mathrm{~mm}$; tip cut straight, but with a fine rounded border) was attached to a micromanipulator. A larva was placed laterally in a curled position under a gauze frame $(3.5 \mathrm{~cm}$ diameter, mesh width: $1.6 \mathrm{~mm})$. The force gauge was moved perpendicular at $0.1 \mathrm{~mm} / \mathrm{s}$ towards the larva, until the needle disrupted the integument. The maximum force applied to the larva was recorded from a digital display.

To obtain information about the reliability of the data, four groups of 50 larvae from our stock were measured repeatedly. The first measurement was taken in all the larvae when they had reached the second day of the final feeding instar. A second measurement was taken at the opposite lateral body side of the same individuals either after $0,3,6$, or $18 \mathrm{~h}$. The maximum force was always measured left to the centre of the larva (in the first measurement the larva's head was placed on the left side, in the second measurement on the right side, or the other way round in half of the larvae measured per treatment)

\section{Analysis of glucosinolate concentration}

Haemolymph samples were lyophilised. Glucosinolates were extracted in $70 \%$ boiling methanol after adding $20 \mu \mathrm{l}$ of benzylglucosinolate as internal standard. Glucosinolate analysis was elaborated by conversion to desulfoglucosinolates as described elsewhere (Agerbirk et al, 2001). For analysis of desulfoglucosinolates, a highperformance liquid chromatograph coupled to a photodiode array UV detector (Waters 990) was equipped with an ODS 2 column (Alltech: Allsphere, length $150 \mathrm{~mm}$, ID $4.6 \mathrm{~mm}$ ). Methanol (15\%) in water was used as solvent, at a flow rate of $1 \mathrm{ml} / \mathrm{min}$. Peaks were quantified by the 
peak area at $226 \mathrm{~nm}$ (bandwidth $4 \mathrm{~nm}$ ) relative to the area of the internal standard peak. The relative response factors reported by McGregor (1985), as cited by Buchner (1987), were used for sinalbin ( $p$-hydroxybenzylglucosinolate) (0.50), and benzylglucosinolate (0.86). Identification of glucosinolates in haemolymph samples of $A$. rosae had been confirmed previously (Müller et al, 2001). In several samples, trace amounts of two unidentified peaks were found, one possibly 1-methylpropylglucosinolate (Müller et al, 2001) and the other with a close retention time and similar spectrum to sinalbin. For both, a response factor of 1 was assumed. Glucosinolate concentration was expressed as total glucosinolate concentration in $\mu \mathrm{mol} / \mathrm{g}$ fresh weight, summing the concentrations of sinalbin and the two unknown glucosinolates (concentration of the latter always $<1 \mu \mathrm{mol} / \mathrm{g}$ fresh weight).

\section{Allozyme analysis}

To compare the populations, male and female adults of the $P$-generation were frozen and analysed for allozyme polymorphism using electrophoresis on cellulose-acetate gels. Staining and buffer recipes were taken from Richardson et al (1986) and Hebert and Beaton (1989). Allozyme data were analysed using GDA, version D12 (Lewis and Zaykin, 1999).

\section{Statistical analysis}

Repeatability of integument resistance measurements was calculated using one-way analysis of variance (ANOVA) (Lessels and Boag, 1987). Heritabilities $\left(h^{2}\right)$ were estimated using offspring-on-parent regression analysis (Falconer and Mackay, 1996) adapted to haplodiploid insects by assuming gene dosage compensation in the haploid males (Liu and Smith, 2000). Sexes were analysed in different ways: $h^{2}=b \times 2(b$ : regression coefficient) for mother-son regression and $h^{2}=b$ for mid-parent-daughter regression. Linear regressions of parents to mean values of offspring were weighted for family size.

Sib analysis was carried out by ANOVA with restricted maximum likelihood estimation and with 'family' as a random factor. Heritabilities were estimated for male sibs as $h^{2}=2 \times \operatorname{Var}$ (family)/[Var(family)+Var(error)] and for female sibs as $h^{2}=4 / 3 \times \operatorname{Var}($ family) /[Var(family)+Var (error)]. Several $P$ females had probably not mated successfully as they only produced sons. Thus, data did not allow the partition of variance into components due to sire and dam nested within sires for female offspring. Heritability estimates of the trait integument resistance were corrected for assortative mating by the formula $h^{2}=\left[-1+\sqrt{ }\left(1+4 r h_{0}^{2}\right)\right] / 2 r$ (where $r$ is the correlation between the father and mother value and $h_{0}^{2}$ is the uncorrected $h^{2}$ estimate) (Falconer and Mackay, 1996). ANOVA was used to test for effects (phenotypic differences) of population and generation. Data were only pooled when there were no significant effects in the latter analysis.

Phenotypic correlations between different traits were estimated by Pearson product-moment correlation of individual measurements. For genetic correlations, means of offspring per family were weighted and analysed by Pearson product-moment correlation.

\section{Results}

\section{Repeatability of integument measurement data}

The repeatability of measurements of the integument resistance was $89 \%$ after $0 \mathrm{~h}(P<0.001, n=48), 62 \%$ after $3 \mathrm{~h}(P=0.01, n=49)$, and $96 \%$ after $6 \mathrm{~h}(P<0.001, n=50)$. These values indicate that most of the variance was among individuals rather than within individuals, and that, therefore, both measurement accuracy (Becker, 1992) and potential heritability was high. When the second measurement was made on the following day after $18 \mathrm{~h}$, data were not repeatable $(r=-0.11, P=0.12$, $n=50)$ indicating the necessity of careful standardisation of timing of integument measurements with respect to developmental stage.

\section{Heritability estimates - male offspring}

Mother-son regressions revealed no statistically significant heritabilities for the traits glucosinolate concentration, integument resistance, eonymph mass, and adult mass in the three populations (glucosinolate concentration only tested for the Swiss population) (Table 1). The lack of significance was partly due to high standard errors (eg in two traits of the French population) and partly because the estimates of $h^{2}$ were close to zero (eg all traits in the Swiss population, Table 1). The developmental time from egg to eonymph and eonymph to adult was significantly heritable only in the German population. The sole trait with no significant differences in phenotype between populations was integument resistance. For all other traits, there were significant effects of populations $(P<0.01$, ANOVA): for eonymph mass, differences in phenotype were significant between the French and Swiss, and Swiss and German populations $(P<0.001$, Scheffé-test); for adult mass, differences were significant between the French and Swiss $(P<0.001)$, and French and German populations $(P=0.04)$; for developmental times, differences were significant between the Swiss and German populations $(P=0.03)$, and for time from eonymph to adult additionally between the French and German populations $(P<0.001)$.

In contrast to mother-son regressions, full-sib analysis of sons revealed highly significant heritabilities in all traits and populations, except body masses of eonymphs and adults which were only significantly heritable in the Swiss population. Mean heritabilites differed between populations but the ranges were overlapping (Table 1).

\section{Heritability estimates - female offspring}

Parent-offspring regressions for female offspring were examined over two generations due to a lack of a sufficient number of female offsprings in one generation. There was a significant effect of generation for the phenotypic values of all traits measured $(P<0.05$, ANOVA; there were significant differences between $F 1$ and F2 for all traits). Furthermore, only three females of the German population produced female offspring and thus, data from this population for this sex could not be analysed.

Mid-parent-daughter regression revealed a statistically significant heritability only for one trait, integument resistance, in one generation (F2) of the French population (Table 2). On the other hand, once again, full-sib analysis of daughters revealed significant heritabilities for all 
Table 1 Narrow-sense heritability estimates for male A. rosae of three populations from France (F), Switzerland (CH), and Germany (D), calculated by parent-offspring regression (linear regression) of quantitative traits between mothers and mean value of sons, weighted for number offspring per family, and by full-sib analysis (ANOVA)

\begin{tabular}{|c|c|c|c|c|c|c|c|}
\hline Trait & Pop. & $\begin{array}{l}\text { Mean } \pm S D \\
\text { mothers }\end{array}$ & $\begin{array}{l}\text { Mean } \pm S D \\
\text { sons }\end{array}$ & Ind. (n) & Fam. (n) & $\mathrm{h}^{2} \pm S E$ parent-offspring & $\mathrm{h}^{2} \pm S E$ full-sib \\
\hline Gls. Conc. & $\mathrm{CH}$ & $19.23 \pm 8.51$ & $13.71 \pm 7.22$ & 186 & 41 & $-0.001 \pm 0.16$ n.s. & $0.35 \pm 0.19^{* * *}$ \\
\hline $\begin{array}{l}\text { Integument } \\
\text { resistance } \\
\text { (g) }\end{array}$ & $\begin{array}{l}\mathrm{F} \\
\mathrm{CH} \\
\mathrm{D} \\
\mathrm{F}+\mathrm{CH}+\mathrm{D}\end{array}$ & $\begin{array}{l}3.09 \pm 0.77 \\
2.92 \pm 0.53 \\
2.80 \pm 0.88 \\
2.93 \pm 0.66\end{array}$ & $\begin{array}{l}2.58 \pm 0.45 \\
2.61 \pm 0.44 \\
2.84 \pm 0.50 \\
2.64 \pm 0.46\end{array}$ & $\begin{array}{r}90 \\
260 \\
72 \\
422\end{array}$ & $\begin{array}{r}19 \\
41 \\
9 \\
69\end{array}$ & $\begin{array}{l}0.34 \pm 0.27 \text { n.s. } \\
0.09 \pm 0.26 \text { n.s. } \\
0.47 \pm 0.39 \text { n.s. } \\
0.24 \pm 0.17 \text { n.s. }\end{array}$ & $\begin{array}{l}\mathbf{0 . 4 4} \pm 0.29^{* *} \\
\mathbf{0 . 3 9} \pm 0.17^{* * *} \\
\mathbf{0 . 5 0} \pm 0.52^{* *} \\
\mathbf{0 . 4 0} \pm 0.14^{* * *}\end{array}$ \\
\hline $\begin{array}{l}\text { Mass } \\
\text { eonymph } \\
(\mathrm{mg})\end{array}$ & $\begin{array}{l}\mathrm{F} \\
\mathrm{CH} \\
\mathrm{D}\end{array}$ & $\begin{array}{l}49.92 \pm 3.70 \\
49.34 \pm 5.82 \\
46.61 \pm 3.21\end{array}$ & $\begin{array}{l}30.93 \pm 1.50 \\
28.53 \pm 2.62 \\
31.71 \pm 1.00\end{array}$ & $\begin{array}{r}89 \\
256 \\
70\end{array}$ & $\begin{array}{r}19 \\
41 \\
9\end{array}$ & $\begin{array}{r}-0.08 \pm 0.20 \text { n.s. } \\
0.03 \pm 0.14 \text { n.s. } \\
0.01 \pm 0.24 \text { n.s. }\end{array}$ & $\begin{array}{l}0.13 \pm 0.19 \text { n.s. } \\
\mathbf{0 . 7 5} \pm 0.24^{* * * *} \\
0.11 \pm 0.18 \text { n.s. }\end{array}$ \\
\hline $\begin{array}{l}\text { Mass } \\
\text { adult } \\
(\mathrm{mg})\end{array}$ & $\begin{array}{l}\mathrm{F} \\
\mathrm{CH} \\
\mathrm{D}\end{array}$ & $\begin{array}{l}22.13 \pm 2.58 \\
21.80 \pm 2.36 \\
21.08 \pm 0.85\end{array}$ & $\begin{array}{l}11.14 \pm 0.75 \\
10.18 \pm 1.01 \\
10.37 \pm 0.85\end{array}$ & $\begin{array}{r}88 \\
253 \\
58\end{array}$ & $\begin{array}{r}19 \\
41 \\
9\end{array}$ & $\begin{array}{r}-0.005 \pm 0.14 \text { n.s. } \\
0.003 \pm 0.14 \text { n.s. } \\
-0.14 \pm 0.43 \text { n.s. }\end{array}$ & $\begin{array}{l}0.22 \pm 0.22 \text { n.s. } \\
\mathbf{0 . 6 9} \pm 0.22^{* * *} \\
0.97 \pm 0.88 \text { n.s. }\end{array}$ \\
\hline $\begin{array}{l}\text { Dev. } \\
\text { egg-eon. } \\
\text { (d) }\end{array}$ & $\begin{array}{l}\mathrm{F} \\
\mathrm{CH} \\
\mathrm{D}\end{array}$ & $\begin{array}{l}18.75 \pm 0.68 \\
19.47 \pm 0.79 \\
18.70 \pm 0.42\end{array}$ & $\begin{array}{l}17.95 \pm 0.80 \\
18.11 \pm 1.53 \\
17.44 \pm 0.86\end{array}$ & $\begin{array}{r}89 \\
256 \\
70\end{array}$ & $\begin{array}{r}19 \\
41 \\
9\end{array}$ & $\begin{array}{l}0.34 \pm 0.56 \text { n.s. } \\
0.07 \pm 0.62 \text { n.s. } \\
3.97 \pm 0.41^{* * *}\end{array}$ & $\begin{array}{l}1.33 \pm 0.62^{* * * *} \\
1.60 \pm 0.40^{* * *} \\
1.70 \pm 0.96^{* * *}\end{array}$ \\
\hline $\begin{array}{l}\text { Dev. } \\
\text { eon.-adult } \\
\text { (d) }\end{array}$ & $\begin{array}{l}\mathrm{F} \\
\mathrm{CH} \\
\mathrm{D}\end{array}$ & $\begin{array}{l}14.15 \pm 0.52 \\
15.42 \pm 0.72 \\
14.14 \pm 0.35\end{array}$ & $\begin{array}{l}16.35 \pm 0.81 \\
15.80 \pm 0.53 \\
15.24 \pm 1.68\end{array}$ & $\begin{array}{r}88 \\
246 \\
58\end{array}$ & $\begin{array}{r}19 \\
41 \\
9\end{array}$ & $\begin{array}{c}1.25 \pm 0.70 \text { n.s. } \\
-0.24 \pm 0.23 \text { n.s. } \\
7.27 \pm 2.39^{*}\end{array}$ & $\begin{array}{l}\mathbf{1 . 2 0} \pm 0.61^{* * *} \\
\mathbf{0 . 6 6} \pm 0.21^{* * *} \\
\mathbf{0 . 9 0} \pm 0.57^{* * *}\end{array}$ \\
\hline
\end{tabular}

Significant differences from zero: ${ }^{*} P<0.05 ;{ }^{* *} P<0.01 ;{ }^{* * *} P<0.001$; n.s. not significant. Statistically significant heritability estimates are highlighted in bold. ind.=individuals; fam. = families; gls-glucosinolate, conc. = concentration $(\mu \mathrm{mol} / \mathrm{g}$ fresh weight); eon. = eonymph; dev. = developmental time. Differences in phenotype between populations were examined by ANOVA. The only trait without a significant population effect is the integument resistance $(P=0.058)$. For all other traits $P<0.01$.

Table 2 Broad-sense heritability estimates for female A. rosae of two populations from France (F), and Switzerland (CH) for two generations $(F 1, F 2)$, calculated by mid-parent-offspring regression (linear regression) of quantitative traits between mean value of parents and mean value of daughters, weighted for number offspring per family, and by full-sib analysis (analysis of variance)

\begin{tabular}{|c|c|c|c|c|c|c|c|}
\hline Trait & Pop./gen. & $\begin{array}{l}\text { Mean } \pm S D \\
\text { mid-parents }\end{array}$ & $\begin{array}{l}\text { Mean } \pm S D \\
\text { daughters }\end{array}$ & $\begin{array}{l}\text { Ind. } \\
(n)\end{array}$ & $\begin{array}{l}\text { Fam. } \\
\text { (n) }\end{array}$ & $\begin{array}{c}\mathrm{h}^{2} \pm S E \\
\text { parent-offspring }\end{array}$ & $\begin{array}{l}\mathrm{h}^{2} \pm S E \\
\text { full-sib }\end{array}$ \\
\hline \multirow{4}{*}{$\begin{array}{l}\text { Integument } \\
\text { resistance } \\
\text { (g) }\end{array}$} & F F1 & $2.66 \pm 0.76$ & $2.63 \pm 0.82$ & 59 & 12 & $0.17 \pm 0.27$ n.s. & $0.43 \pm 0.28^{* *}$ \\
\hline & F F2 & $2.70 \pm 1.16$ & $3.12 \pm 0.61$ & 61 & 12 & $0.33 \pm 0.07^{* * *}$ & $0.48 \pm 0.31^{* * *}$ \\
\hline & $\mathrm{CH} F 1$ & $2.81 \pm 0.53$ & $2.44 \pm 0.64$ & 49 & 10 & $-0.04 \pm 0.30$ n.s. & $\mathbf{0 . 4 3} \pm 0.41^{* *}$ \\
\hline & $\mathrm{CH} F 2$ & $2.40 \pm 0.90$ & $3.03 \pm 0.64$ & 81 & 13 & $-0.006 \pm 0.07$ n.s. & 0 n.s. \\
\hline \multirow{4}{*}{$\begin{array}{l}\text { Mass } \\
\text { eonymph } \\
(\mathrm{mg})\end{array}$} & F F1 & $40.99 \pm 2.59$ & $51.995 \pm 3.996$ & 59 & 12 & $0.47 \pm 0.32$ n.s. & $0.36 \pm 0.26^{* *}$ \\
\hline & F F2 & $40.22 \pm 2.35$ & $51.79 \pm 5.12$ & 61 & 12 & $0.07 \pm 0.37$ n.s. & $0.17 \pm 0.17$ n.s. \\
\hline & $\mathrm{CH} F 1$ & $38.51 \pm 2.34$ & $45.95 \pm 4.72$ & 48 & 10 & $0.21 \pm 0.40$ n.s. & $0.24 \pm 0.30$ n.s. \\
\hline & $\mathrm{CH} F 2$ & $37.43 \pm 3.25$ & $49.67 \pm 6.79$ & 81 & 13 & $0.02 \pm 0.26$ n.s. & $0.04 \pm 0.10$ n.s. \\
\hline \multirow{4}{*}{$\begin{array}{l}\text { Mass } \\
\text { adult } \\
(\mathrm{mg})\end{array}$} & F F1 & $17.16 \pm 2.17$ & $21.55 \pm 1.58$ & 55 & 12 & $0.05 \pm 0.16$ n.s. & $0.32 \pm 0.27^{*}$ \\
\hline & F F2 & $15.98 \pm 1.25$ & $22.18 \pm 2.35$ & 60 & 12 & $0.37 \pm 0.34$ n.s. & $0.22 \pm 0.20^{*}$ \\
\hline & $\mathrm{CH} F 1$ & $16.60 \pm 1.80$ & $19.85 \pm 1.67$ & 45 & 10 & $-0.02 \pm 0.16$ n.s. & 0 n.s. \\
\hline & $\mathrm{CH} F 2$ & $14.97 \pm 1.02$ & $21.50 \pm 3.03$ & 81 & 13 & $0.55 \pm 0.33$ n.s. & $0.07 \pm 0.12$ n.s. \\
\hline Dev. & F F1 & $17.75 \pm 0.45$ & $19.05 \pm 1.65$ & 59 & 12 & $-0.74 \pm 0.12$ n.s. & $1.13 \pm 0.55^{* * *}$ \\
\hline \multirow{3}{*}{$\begin{array}{l}\text { egg-eon. } \\
\text { (d) }\end{array}$} & F F2 & $18.33 \pm 0.91$ & $16.62 \pm 0.93$ & 61 & 12 & $-0.14 \pm 0.26$ n.s. & $0.83 \pm 0.44^{* * *}$ \\
\hline & $\mathrm{CH} F 1$ & $18.65 \pm 0.97$ & $19.25 \pm 1.18$ & 48 & 10 & $-0.12 \pm 0.34$ n.s. & $0.95 \pm 0.57^{* * *}$ \\
\hline & $\mathrm{CH} F 2$ & $18.23 \pm 1.09$ & $16.33 \pm 1.26$ & 81 & 13 & $0.11 \pm 0.30$ n.s. & $1.06 \pm 0.49^{* * *}$ \\
\hline \multirow{4}{*}{$\begin{array}{l}\text { Dev. } \\
\text { eon.-adult } \\
\text { (d) }\end{array}$} & F F1 & $14.00 \pm 0.83$ & $15.25 \pm 0.97$ & 55 & 12 & $0.32 \pm 0.31$ n.s. & $0.89 \pm 0.48^{* * *}$ \\
\hline & F F2 & $15.58 \pm 0.70$ & $14.77 \pm 1.00$ & 60 & 12 & $0.30 \pm 0.37$ n.s. & 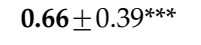 \\
\hline & $\mathrm{CH} F 1$ & $15.85 \pm 0.47$ & $14.28 \pm 1.03$ & 46 & 10 & $-0.28 \pm 0.66$ n.s. & $\mathbf{0 . 7 8} \pm 0.50^{* * *}$ \\
\hline & $\mathrm{CH} F 2$ & $15.19 \pm 0.56$ & $14.58 \pm 0.72$ & 81 & 13 & $0.09 \pm 0.27$ n.s. & 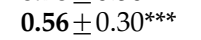 \\
\hline
\end{tabular}

Significant differences from zero: ${ }^{*} P<0.05 ;{ }^{* *} P<0.01 ;{ }^{* * *} P<0.001$; n.s. not significant. Statistically significant heritability estimates are highlighted in bold. ind. = individuals; fam. = families; eon. = eonymph; dev. = developmental time. 
Table 3 Phenotypic (P) and genetic $(\mathrm{G})$ correlations (Pearson product-moment correlation) between quantitative traits, measured in males (F2) of the Swiss population of A. rosae

\begin{tabular}{|c|c|c|c|c|c|c|c|c|c|c|}
\hline \multirow[t]{2}{*}{ Trait } & \multicolumn{2}{|c|}{ Integument resistance } & \multicolumn{2}{|c|}{ Glucosinolate conc. $(G c)$} & \multicolumn{2}{|c|}{ Mass eonymph $(\mathrm{Me})$} & \multicolumn{2}{|c|}{ Mass adult (Ma) } & \multicolumn{2}{|c|}{ Dev. Egg-eon. (De) } \\
\hline & $P$ & G & $P$ & G & $P$ & $G$ & $P$ & $G$ & $P$ & $G$ \\
\hline Gc & -0.13 N.S. & 0.02N.S. & & & & & & & & \\
\hline $\mathrm{Me}$ & -0.03 N.S. & 0.01N.S. & $0.15^{*}$ & $0.37^{* * *}$ & & & & & & \\
\hline Ma & -0.04 N.S. & -0.09 N.S. & 0.12N.S. & $0.25^{* * *}$ & $0.71^{* * *}$ & $0.77^{* * *}$ & & & & \\
\hline De & $0.16^{*}$ & $0.37^{* * *}$ & 0.13N.S. & 0.14N.S. & 0.01N.S. & 0.04N.S. & $-0.21^{* *}$ & $-0.29^{* * *}$ & & \\
\hline $\mathrm{Da}$ & -0.06 N.S. & -0.13 N.S. & $-0.16^{*}$ & $-0.31^{* * *}$ & -0.04 N.S. & -0.17 N.S. & -0.20 N.S. & -0.07 N.S. & 0.02N.S. & 0.12N.S. \\
\hline
\end{tabular}

Significant differences from zero: ${ }^{*} P<0.05 ;{ }^{* *} P<0.01 ;{ }^{* * *} P<0.001 ;$ n.s. not significant. Statistically significant correlations are highlighted in bold. conc. $=$ concentration; dev. $=$ developmental time; eon. $=$ eonymph; Da: dev. eon.-adult.

traits measured in the French population in both generations except the eonymph mass of the F2. In the Swiss population, integument resistance was heritable in one generation (F1) and developmental times in both generations (Table 2).

\section{Correlations among different traits}

Significantly positive phenotypic correlations between the mass of the eonymphs and of the adults were found in all the generations and populations $(r>0.5, P<0.01)$. A detailed overview of the correlations is given for the male offspring of the Swiss population (Table 3 and Figure 1) since this population is also representative of the other two. Glucosinolate concentration showed a negative phenotypic relation with integument resistance although the correlation did not reach significance. Furthermore, this chemical trait was positively correlated with the eonymph mass, but negatively with developmental time from eonymph to adult (Figure 1), although again these correlations were rather low and levels of significance weak. The genetic correlations were of the same sign but stronger than the phenotypic correlations in several cases, for example, those between glucosinolate concentration and either body mass or developmental time (Table 3). However, there was no indication of any genetic correlation between the two defensive traits.

\section{Allozyme analysis}

The $F_{\mathrm{ST}}$ values for males and females of the investigated populations are low and indicate 'little' genetic differentiation (according to the classification of Hartl and Clark, 1997) (Table 4).

\section{Discussion}

This study is the first to examine the quantitative genetics of an insect chemical defence mechanism that involves several traits, namely the concentration of a deterrent compound and an integument adaptation. Although because of the fact that some females produced no or only male offspring, sample sizes are lower than we had planned, some clear results were obtained. Most heritability estimates for both defence and life-history traits in the sawfly $A$. rosae were significant when analysing full-sib data but not when regressing offspring on parents. Full-sib analysis often overestimates heritability compared to parent-offspring regression, because of both dominance variance and common environments for sibs. However, as highly significant values were also obtained for male full-sibs, where no dominance variance is present, the common environment issue is more important. Such common environment conditions result in a small within-family variation and thus heritabilities for the full-sib-analysis are inflated as within-family variation forms the denominator in the estimates. Detailed explanations for possible causes of the differences between heritability estimates in A. rosae are given in the following discussion of the individual traits.

The chemical trait of glucosinolate concentration in the haemolymph of $A$. rosae showed significant genetic variation ( $\left.h^{2}=0.35 \pm 0.19\right)$ when analysing full-sib data (Table 1). The glucosinolate concentration serves as an indicator for the deterrence of the haemolymph towards predators such as ants (Müller et al, 2002). In the leaf beetle Oreina gloriosa (Coleoptera: Chrysomelidae), the concentration of defensive compounds secreted by adults was significantly heritable in estimates of full-sib analysis $\left(h^{2}=0.57\right)$, and of mother-offspring regression $\left(h^{2}=0.51\right)$ (Eggenberger and Rowell-Rahier, 1992). The defensive secretion of $O$. gloriosa contains a complex mixture of cardenolides and ethanolamines that are not sequestered but synthesised de novo (Rowell-Rahier et al, 1995) and thus are unlikely to be dependent on hostplant quality. In contrast, for $A$. rosae the host-plant quality is crucial for the concentration of the defence compound in the haemolymph. Analysis of experiments involving switching larvae to host plants with other glucosinolate profiles during the last feeding of larval instar revealed that the glucosinolate composition of the larval haemolymph corresponds to that of the new leaf in a very short time: after $20 \mathrm{~h}$ it closely resembles the new host (Müller, unpublished). In the full-sib experiment, we minimised the effects of common environment for families by placing larvae individually at least 2 days before sampling of haemolymph on randomised leaves in Petri dishes. After this time, the glucosinolate concentration of the haemolymph will be more influenced by the quality of that particular leaf than the previous food supply. Furthermore, it might be affected by the ability of the larva to concentrate glucosinolates 
a

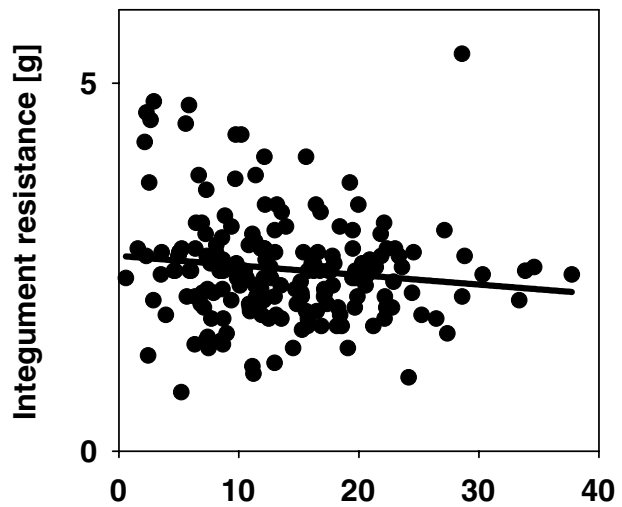

b

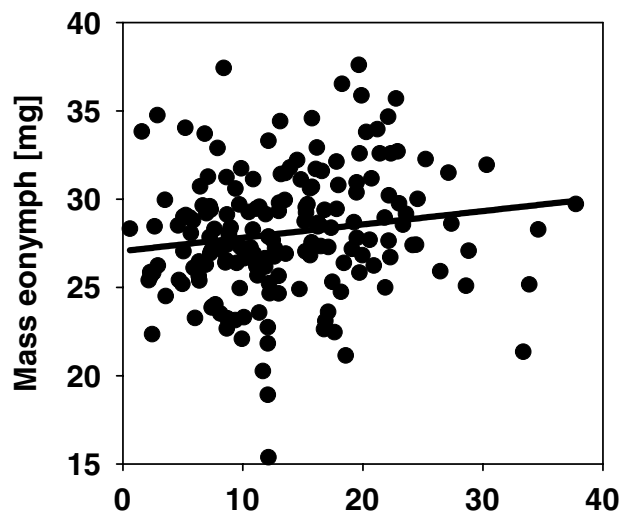

C

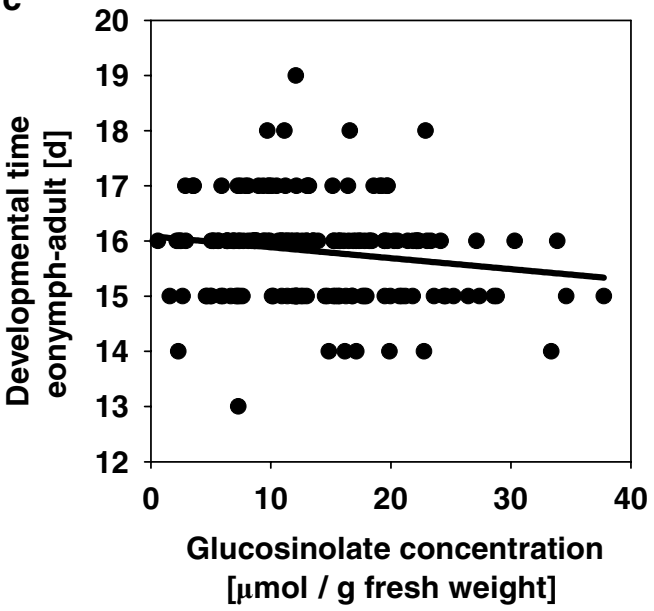

Figure 1 Regression of different traits on the glucosinolate concentration (as measurement for deterrence) in males of the Swiss population of $A$ rosae. For $r$ - and $P$-values refer to the phenotypic correlations in Table 3.

up to a certain threshold level. Although our S. alba plants were all grown from the same seed source and under the same environmental conditions, their glucosinolate content and overall quality may have differed between batches used for subsequent generations, as it does in many Brassicaceae due to seasonal variation and induction events (Rosa, 1997; Agrawal et al, 1999. Agerbirk et al, 2001). This could explain the observed lack of correlation between haemolymph glucosinolate concentrations for parents and their offspring in $A$. rosae.

For integument resistance, the full-sib analysis revealed for male and female siblings in all the three populations
Table $4 F_{\mathrm{ST}}$-values for $A$. rosae populations from Switzerland $(\mathrm{CH})$, France (F) and Germany (D) obtained by allozyme electrophoresis

\begin{tabular}{lccccc}
\hline Sex & overall & CH/F & CH/D & F/D & n Total \\
\hline Male & 0.03 & 0.07 & 0.01 & 0.05 & 49 \\
Female & - & 0.05 & N.D. & N.D. & 94
\end{tabular}

Analysis of nine different loci from the enzymes (malate dehydrogenase, $\mathrm{MDH}$; 1.1.1.37), (malic enzyme, ME; 1.1.1.40), (isocitrate dehydrogenase, IDH; 1.1.1.42), (aspartate aminotransferase, AAT; 2.6.1.1), ( $\beta$-esterase, $\beta$-est.; 3.1.1.1), (glucose-6-phosphate isomerase, GPI; 5.3.1.9), and (phosphoglucomutase, PGM; 5.4.2.2) (nomenclature following Murphy et al, 1996, EC numbers given). Presence of private alleles: two in Swiss, and two in French females. No linkage disequilibrium was detected. N.D., not detected.

moderate heritability estimates of about 0.4 (0.38-0.50). The similarity between female and male heritability estimates suggests that dominance variance is of minor influence on this trait (brother-brother analysis estimates narrow-sense heritability only). This may in turn indicate that selection on this particular trait is low and may be over-riden by environmental variance (Crnokrak and Roff, 1995). The integument resistance measurements on living larvae are a sum of the integument strength and the hydraulic pressure of the haemolymph. Hydration has a marked effect on the integument properties (Hepburne and Joffe, 1976) which is dependent on environmental conditions such as humidity and hostplant quality. Variation in these factors during the experiment might again account for the absence of significant correlations between measurements from different generations. For the integument resistance, the timing of measurement is critical and closely linked to the moulting cycle of the larvae. Our measurement in the mid-phase of the last feeding larval instar is highly repeatable, while measurements closer to the end of the phase are no longer comparable probably because the new integument of the eonymph is already formed under the larval cuticula. To our knowledge, heritabilities of integument resistance have not been estimated for other insects.

The life-history traits of body mass of eonymphs and of adults were only significantly heritable in some populations/generations. Where significant, heritabilities varied between $0.22 \pm 0.20$ (Table 2) and $0.75 \pm 0.24$ (Table 1). In other haplodiploid sawflies, heritabilities for body mass estimated by half-sib analysis were comparable [eg 0.38 , SE not given, Sequeira and Mackauer, 1992; 0.55 \pm 0.15 , Kause et al, 2001]. For developmental time, very high values for heritabilites were found for full-sib analysis of all $A$. rosae populations and generations. However, some caution is needed in interpreting our estimates because they have rather high and overlapping standard errors. Furthermore, those for developmental time are likely to be even more sensitive to common environment effects, especially in early development where larvae shared environments. A high variation of estimated heritabilities for morphological and life-history traits is typical for many studies including other sawflies (eg Chenot and Raffa, 1998). Furthermore, for several tree feeding sawfly species, it has been shown that plant chemistry can have a strong effect, particularly on developmental time (Geri et al, 1993). 
Differences in heritabilities were found between the $A$. rosae populations, most strikingly in the trait body mass. Such differences could indicate different histories of selection, for example, due to regional climates and habitat diversity. A high variation in heritability estimates for body size of wild populations along a latitudinal gradient has been demonstrated for Drosophila (van 't Land et al, 1999). Differences between populations could also be because of different founder effects or bottleneck events resulting in loss of genetic variation or inbreeding depression (eg Saccheri et al, 1996). Molecular markers are a practical tool for investigating such effects (eg Brown et al, 1997; de Jong et al, 2001). Allozyme analyses of $A$. rosae revealed little genetic variation between the three populations (Table 4). Thus, the differences found in heritability estimates might be partly explained by differences in genetic history. However, molecular variability has only a limited ability to predict quantitative genetic variability (Reed and Frankham, 2001), making a different history of selection the most likely reason for the differences between populations.

A high phenotypic and genetic correlation between the body mass of eonymph and adult was consistently found in all the three $A$. rosae populations. However, all the other phenotypic correlations between the quantitative traits were weak (Table 3). Body mass and developmental time of larvae have been shown to be clearly positively correlated in a comparative study on six birchfeeding sawfly species when food was of stable high quality and constraints on long development were relaxed (Kause and Morin, 2001; Kause et al, 2001). Seasonal variation of host-plant quality has a major influence on the phenotypic and genotypic architecture of this insect guild (Kause et al, 2001). The influence of host-plant quality on the performance of $A$. rosae is the subject of further studies.

Within $A$. rosae, a high concentration of glucosinolates in the haemolymph seems to be linked to a high eonymph weight and a short developmental time from eonymph to the adult stage, as indicated by the respective signs for the phenotypic and genetic correlations between these traits, Table 3, Figure 1). Thus, there is no obvious trade-off involved in sequestration of the chemical defence compound. There was no significant phenotypic correlation between the two defence traits integument resistance and haemolymph deterrence; however, the sign of this correlation was negative (Figure 1). A clearly significant negative correlation between these traits has been demonstrated among tenthredinid species where haemolymph deterrence was measured in bioassays with $M$. rubra (Boevé and Schaffner, 2003). The link between these traits is thought to be functionally, rather than physiologically based, and to have evolved under the selection pressure of predation (Boevé and Schaffner, 2003). The correlation might represent an emergent property, becoming more obvious only when a wide range of differences in the traits are considered, as has been reported recently for egg size in relation to adult body size between and within butterfly species (Fischer et al, 2002).

Heritabilities in $A$. rosae both for life-history traits and defence traits of a chemical nature appeared to depend on the level of relatedness used to estimate them, probably because of their high sensitivity to environ- mental effects. These are likely to arise from the tight coupling of the insect herbivore traits to host-plant quality and chemistry. In the field, sawfly larvae are confronted with an even wider range of plant nutrients and plant secondary compounds than in our laboratory conditions. Our findings imply that genetic variation is unlikely to be visible in the field as it will be readily overshadowed by environmental variation. However, there is clearly some potential for adaptive evolution in A. rosae, for example, in response to progressive change in environmental conditions. Such genetic variation within species must have been the basis for evolution of phenotypic differences found across species. The apparent profound effects of a variable host plant on the chemical defence trait may have also led to maintenance of genetic variation in the sawfly populations for traits that are potentially closely related to fitness.

\section{Acknowledgements}

We thank A Barker (Switzerland) for providing us with larvae of $A$. rosae, J Prijs and M Heijmans for technical assistance; $N$ Würzer and M Lavrijsen for the supply of mustard plants; A Kause (Finland), K Fischer (Leiden), and J-L Boevé (Belgium) for useful improvements on the manuscript. This research was supported by the European Community's Improving Human Potential Programme under contract HPRN-CT-1999-00054, INCHECO.

\section{References}

Agerbirk N, Olsen CE, Nielsen JK (2001). Seasonal variation in leaf glucosinolates and insect resistance in two types of Barbarea vulgaris ssp. arcuata. Phytochemistry 58: 91-100.

Agrawal AA, Gorski PM, Tallamy DW (1999). Polymorphism in plant defense against herbivory: constitutive and induced resistance in Cucumis sativus. J Chem Ecol 25: 2285-2304.

Becker WA (1992). Manual of Quantitative Genetics. Academic Enterprises; Pullman, WA.

Boevé J-L, Schaffner U (2003). Why does the larval integument of some sawfly species disrupt so easily? The harmful hemolymph hypothesis. Oecologia 134: 104-111.

Brown RJ, Malcolm CA, Mason PL, Nichols RA (1997). Genetic differentiation between and within strains of the saw-toothed grain beetle, Oryzaephilus surinamensis (Coleoptera: Silvanidae) at RAPD loci. Insect Mol Biol 6: 285-289.

Buchner R (1987). Approach to determination of HPLC response factors for glucosinolates. In: Wathelet J-P (ed) Glucosinolates in Rapeseeds: Analytical Aspects. Martinus Nijhoff Publishers: Dordrecht. pp 50-58.

Camara MD (1997). Predator responses to sequestered plant toxins in buckeye caterpillars: Are tritrophic interactions locally variable? J Chem Ecol 23: 2093-2106.

Chenot AB, Raffa KF (1998). Heritability estimates of development time and size characters in the gypsy moth (Lepidoptera: Lymantriidae) parasitoid Cotesia melanoscela (Hymenoptera: Braconidae). Environ Entomol 27: 415-418.

Codella SG, Raffa KF (1993). Defense strategies of folivorous sawflies. In: Wagner MR, Raffa KF (eds) Sawfly Life History. Adaptations to Woody Plants. Academic Press: San Diego. pp 261-294.

Crnokrak P, Roff DA (1995). Dominance variance: associations with selection and fitness. Heredity 75: 530-540.

de Jong PW, de Vos H, Nielsen JK (2001). Demic structure and its relation with the distribution of an adaptive trait in Danish flea beetles. Mol Ecol 10: 1323-1332. 
Eggenberger F, Rowell-Rahier M (1992). Genetic component of variation in chemical defense of Oreina gloriosa (Coleoptera, Chrysomelidae). J Chem Ecol 18: 1375-1404.

Falconer DS, Mackay TFC (1996). Introduction to Quantitative Genetics, 4th edn. Pearson Education: Harlow.

Fischer K, Zwaan BJ, Brakefield PM (2002). How does egg size relate to body size in butterflies? Oecologia 131: 375-379.

Geri C, Allais JP, Auger M-A (1993). Effects of plant chemistry and phenology on sawfly behavior and development. In: Wagner MR, Raffa KF (eds) Sawfly Life History. Adaptations to Woody Plants. Academic Press: San Diego. pp 173-210.

Hartl DL, Clark AG (1997). Principles of Population Genetics. Sinauer Associates, Inc.: Sunderland, MA.

Hebert PDN, Beaton MJ (1989). Methodologies for Allozyme Analysis Using Cellulose Acetate Electrophoresis: A Practical Handbook. Helena laboratories: Texas.

Hepburn HR, Joffe I (1976). On the material properties of insect exoskeletons. In: Hepburn HR (ed) The Insect Integument, Elsevier Scientific Publishing Company: Amsterdam. pp 207-235.

Holloway GJ, de Jong PW, Ottenheim M (1993). The genetics and cost of chemical defense in the two-spot ladybird (Adalia bipunctata L.). Evolution 47: 1229-1239.

Kause A, Morin J-P (2001). Seasonality and genetic architecture of development time and body size of the birch feeding sawfly Priophorus pallipes. Genet Res Camb 78: 31-40.

Kause A, Saloniemi I, Morin JP, Haukioja E, Hanhimaki S, Ruohomaki K (2001). Seasonally varying diet quality and the quantitative genetics of development time and body size in birch feeding insects. Evolution 55: 1992-2001.

Lessels CM, Boag PT (1987). Unrepeatable repeatabilities: a common mistake. Auk 104: 116-121.

Lewis PO, Zaykin DZ (1999). Genetic Data Analysis: Computer program for the analysis of allelic data. Version 1.0 (D12). [WWW Document]. Free program distributed by the authors over the internet from the GDA home page at URL http:/ / alleyn.eeb.uconn.edu/gda/.

Liu F-H, Smith SM (2000). Estimating quantitative genetic parameters in haplodiploid organisms. Heredity 85: 373-382.

McGregor DI (1985). Determination of glucosinolates in Brassica seed. EUCARPIA Cruciferae Newslett 10: 132-136.

Merilä J, Björklund M (1999). Population divergence and morphometric integration in the greenfinch (Carduelis chloris) - evolution against the trajectory of least resistance. J Evol Biol 12: 103-112.

Müller C, Agerbirk N, Olsen CE, Boevé J-L, Schaffner U, Brakefield PM (2001). Sequestration of host plant glucosino- lates in the defensive hemolymph of the sawfly Athalia rosae. I Chem Ecol 27: 2505-2516.

Müller C, Boevé J-L, Brakefield PM (2002). Host plant derived feeding deterrence towards ants in the turnip sawfly Athalia rosae. Entomol Exp Appl 104: 153-157.

Murphy Jr RW, Sites JW, Buth DG, Haufler CH (1996). Proteins: isozyme electrophoresis. In: Hillis DM, Moritz C, Mable BK (eds) Molecular Systematics, 2nd edn. Simauer: Sunderland, MA. pp 51-120.

Ohara Y, Nagasaki K, Ohsaki N (1993). Warning coloration in sawfly Athalia rosae larva and concealing coloration in butterfly Pieris rapae larva on similar plants evolved through individual selection. Res Popul Ecol (Kyoto) 19: 223-230.

Reed DH, Frankham R (2001). How closely correlated are molecular and quantitative measures of genetic variation? A meta-analysis. Evolution 55: 1095-1103.

Richardson BJ, Baverstock PR, Adams M (1986). Allozyme electrophoresis. A Handbook For Animal Systematics and Population Studies. Academic Press: Sydney.

Rosa EAS (1997). Daily variation in glucosinolate concentrations in the leaves and roots of cabbage seedlings in two constant temperature regimes. J Sci Food Agric 73: 364-368.

Rowell-Rahier M, Pasteels JM, Alonsomejia A, Brower LP (1995). Relative unpalatability of leaf beetles with either biosynthesized or sequestered chemical defense. Anim Behav 49: 709-714.

Saccheri IJ, Brakefield PM, Nichols RA (1996). Severe inbreeding depression and rapid fitness rebound in the butterfly Bicyclus anynana (Satyridae). Evolution 50: 2000-2013.

Sawa M, Oishi K (1989). Studies on the sawfly, Athalia rosae (Insecta, Hymenoptera, Tenthredinidae) II. Experimental activation of mature unfertilized eggs. Zool Sci (Tokyo) 6: 549-556.

Schaffner U, Boevé J-L, Gfeller H, Schlunegger UP (1994). Sequestration of Veratrum alkaloids by specialist Rhadinoceraea nodicornis Konow (Hymenoptera, Tenthredinidae) and its ecoethological implications. J Chem Ecol 20: 32332250.

Schluter D (1996). Adaptive radiation along genetic lines of least resistance. Evolution 50: 1766-1774.

Sequeira R, Mackauer M (1992). Quantitative genetics of body size and developmental time in the parasitoid wasp Aphidius ervi (Hymenoptera, Aphidiidae). Can J Zool 70: 1102-1108.

van't Land J, van Putten P, Zwaan BJ, Kamping A, van Delden W (1999). Latitudinal variation in wild populations of Drosophila melanogaster: heritabilities and reaction norms. J Evol Biol 12: 222-232. 